\title{
Safety of Mesenchymal Stem Cells Therapy in Patients with Inflammatory Bowel Diseases - 5 Year Follow-up
}

Knyazev Oleg Vladimirovich ${ }^{1 *}$, Parfenov Asfold Ivanovich ${ }^{2}$, Konoplaynnikov Anatoliy Georgievich ${ }^{3}$, Kagramanova Anna Valeryevna $^{4 *}$, Churikova Alevtina Alekseevna ${ }^{5}$, Ruchkina Irina Nikolaevna ${ }^{6}$, Lishinskaya Albina Aleksandrovna ${ }^{7}$, Boldireva Oksana Nikolaevna $^{8}$, and Fadeeva Nina Aleksandrovna ${ }^{9}$

${ }^{I}$ Doctor of science, Head of department of treatment inflammatory bowel diseases, Moscow Clinical Research Center

${ }^{2}$ Doctor of Science, professor, Head of intestinal pathology department, Moscow Clinical Research Center

${ }^{3}$ Doctor of science, professor, head of experimental radiotherapy, Moscow Clinical Research Center

${ }^{4}$ Candidate of science, scientist researcher, Moscow Clinical Research Center

${ }^{5}$ Candidate of science, senior scientist, Moscow Clinical Research Center

${ }^{6}$ Doctor of Science, Head scientist of department of inflammatory bowel diseases, Moscow Clinical Research Center

${ }^{7}$ Candidate of science, scientist researcher of department of inflammatory bowel diseases, Moscow Clinical Research Center

${ }^{8}$ Candidate of science, junior scientist researcher of department of inflammatory bowel diseases, Moscow Clinical Research Center

${ }^{9}$ Junior scientist researcher of department of inflammatory bowel diseases, Moscow Clinical Research Center

"Corresponding authors: Knyazev Oleg Vladimirovich, Doctor of science, Head of department of treatment inflammatory bowel diseases, Moscow Clinical Research Center, Russia, E-mail: oleg7@bk.ru

Anna Kagramanova, Candidate of science, scientist researcher, Moscow Clinical Research Center, Russia, Tel: +79260804444; E-mail: kagramanova@me.com

Received Date: 02 ${ }^{\text {nd }}$ June 2015

Accepted Date: $20^{\text {th }}$ July 2015

Published Date: $24^{\text {th }}$ July 2015
Citation: Oleg Vladimirovich K, Asfold Ivanovich P, Anatoliy Georgievich K, Anna Valeryevna K, Alevtina Alekseevna C (2015) Safety of Mesenchymal Stem Cells Therapy in Patients with Inflammatory Bowel Diseases - 5 Year Follow-up. Enliven: J Genet Mol Cell Biol 2(1): 002.

Copyright: @ 2015 Dr. Knyazev Oleg Vladimirovich. This is an Open Access article published and distributed under the terms of the Creative Commons Attribution License, that permits unrestricted use, distribution and reproduction in any medium, provided the original author and source are credited.v

\begin{abstract}
Aim

To compare safety profile of therapy in patients with ulcerative colitis (UC) and Crohn disease (CD), receiving anti-inflammatory therapy, using bone marrow-derived mesenchymal stromal cells (MSC) and standard therapy with 5-aminosalicylic acid (5-ASA), glucocorticosteroids (GCS) and immunosuppressive agents (IS).
\end{abstract}

Materials and Methods

Adverse events were analyzed in 103 patients with inflammatory bowel disease (IBD) after administration MSCs (56 patients UC and 47 patients CD). The findings were compared with data obtained in 208 patients with UC and CD, receiving standard anti-inflammatory therapy. All analyzed patients were similar in demographic characteristics, the duration of disease, the extent of disease, course of disease, phenotype and degree of disease.

The analyzed groups did not include patients, treated with anti-TNF therapy. The safety of therapy was evaluated by presence of complications, developed during follow-up period.

Results

We conducted analysis of side effects in 103 IBD patients, treated with mesenchymal stem cells, comparing with 208 UC and CD patients, treated with standard anti-inflammatory therapy and finally we did not reveal any differences in developing acute posttransfusional toxicity, infectious complications, exacerbation of chronic inflammatory diseases, serious infectious complications, malignancy and death in UC and CD patients, besides transitive febrile. 
Conclusion

Results of our study show that innovative method of cell therapy is safe in clinical practice.

Keywords: Safety of cell therapy; Mesenchymal stromal cells; Crohn disease; Ulcerative colitis; Inflammatory bowel diseases

\section{Introduction}

Mesenchymal stromal cells (mesenchymal stem cells; MSC) are a heterogeneous group of cells, that can be isolated from many tissues (bone marrow, adipose tissue, dental pulp). First described in 1960-years of XX century [1], MSC have recently received attention in a number of different clinical fields for their potential therapeutic effects.

Although often described as «adult stem cells», MSC's have limited cellular differentiation ability. Instead, pre-clinical evidence suggests that MSCs exert their beneficial effects largely through immunomodulatory and paracrine mechanisms. MSCs home to sites of inflammation and secrete bioactive molecules, and thus may be especially effective in different proinflammatory diseases [2].

There is a growing body of literature demonstrating the efficacy of MSC therapy in a variety of pre-clinical models, including acute lung injury $[3,4]$, septic shock [5], acute myocardial infarction [6]. Several small clinical trials have investigated efficacy and safety of MSCs in diseases including chronic heart failure, acute myocardial infarction, hematological malignancies, Crohn disease [7] and graft-versus-host disease.

However, safety concerns represent a significant barrier to the successful translation of MSCs into an acceptable clinical therapeutic. Potential risk is associated with its proliferative capacity, susceptibility to infectious complications given their immunosuppressive effects, embolism of the cells, zoonoses associated with cell culture reagents, and acute or chronic immunogenicity of the cells themselves [8].

Therefore, we conducted a systematic review of randomized and nonrandomized controlled trials as well as uncontrolled clinical trials in foreign literature, which examined the safety and efficacy of intravascularly delivered MSCs, and revealed their most frequent adverse events [9]. Adverse events were grouped according to the immediacy of the event -acute infusional toxicity, fever, the occurrence of organ system complications (neurological, pulmonary, cardiovascular, gastrointestinal and renal, and hematologic systems), infection, and the occurrence of longer term adverse effects (death, malignancy).

Included studies were conducted in 14 different countries from Asia, the Middle East, Europe, and North America. There were eight RCTs ( $n=369$ patients) [10-17], 10 non-RCTs ( $\mathrm{n}=466$ patients) [18-27] and 18 uncontrolled clinical trials $(\mathrm{n}=252$ patients) [28-45]. Six of 36 studies were multi-centre $[12,13,20,23,32,33]$. One non-controlled study had a mixed adult-pediatric population [39], all other studies included only adult participants. The follow-up period was reported in all studies and the duration ranged from 0.5 to 60 months.
There were following diseases analyzed: eight randomized controlled studies included patient populations with cardiovascular diseases-acute myocardial infarction [11,12], chronic heart failure [10,16], with neurological disease either ischemic stroke [13], spinal cord injury [17], following stem cell transplantation for hematological malignancies [15]. The 10 non-RCTs included patient populations with old myocardial infarctions [25], stem-cell transplant post renal transplant[27], stem cell transplant for hematological malignancy $[18,19,23]$, graft-versus-host disease [20,26], or healthy volunteers [24].

Sixteen studies used autological MSC [10,11,13,14,16,17,22,24,25,27,2 $9,31,32,37,43,45]$, eight used allogenic MSC [12,18,20,34,35,39,40,41]. Nine of the 36 studies cryopreserved MSCs prior to administration $[12,18,20,21,23,29,31,32,44]$, and one study used both fresh and cryopreserved MSC [33], while the remainder of studies used only fresh MSCs. A meta-analysis revealed no significant differences in the occurrence of acute infusional toxicity, infectious complications, recurrence of chronic inflammatory diseases, serious infectious complications, malignancy and death between patients treated with MSC and control group. Significant association was demonstrated between MSC injection and transient fever.

Further we demonstrate our data for safety profile of allogenic mesenchymal stromal bone marrow cells in patients with inflammatory bowel diseases over a 5-year follow-up period.

\section{Aim of Study}

To compare safety profile of therapy in patients with ulcerative colitis (UC) and Crohn disease (CD), received combined anti-inflammatory therapy including MSC and standard therapy, including 5-ASA, Glucocorticosteroids (GCS) and immunosuppressive therapy.

\section{Materials and Methods}

Systemic transplantation of allogenic bone marrow MSC was performed in 74 UC and 64 CD patients ranging from 2008 to 2014 years.

First analyzed group included 56 UC patients, follow-up period comprised in median $62 \pm 4$ months. This group consists of 29 (51,78\%) man and 27 $(48,22 \%)$ women (Table 1,2,3). Mean age was $35,4 \pm 1,42$ years. The second control group included $84 \mathrm{UC}$ patients, receiving standard anti-inflammatory therapy with 5-ASA and GCS. This group consists of $46(54,8 \%)$ man and 38 $(45,2 \%)$ women. Mean age - 34,98 $\pm 1,23$ years. 
Table 1 Demographic characteristics of patients with CD and UC

\begin{tabular}{|l|l|l|}
\hline & Male-to-female ratio (\%) & Mean Age, years \\
\hline 1 group $(\mathrm{n}=56)$ & $29: 27(51: 48)$ & $35,4 \pm 1,42$ \\
\hline 2 group $(\mathrm{n}=84)$ & $46: 38(54: 45)$ & $34,98 \pm 1,23$ \\
\hline 3 group $(\mathrm{n}=47)$ & $19: 28(40: 59)$ & $30,4 \pm 1,2$ \\
\hline 4 group $(\mathrm{n}=124)$ & $56: 68(45: 54)$ & $36,8 \pm 1,5$ \\
\hline
\end{tabular}

Table 2 Summary analysis of side effects in UC patients, receiving MSC and in control group

\begin{tabular}{|l|l|l|c|c|}
\hline Side effects in all analyzed clinical trials & $\begin{array}{l}\text { Frequency in 1 group } \\
\text { UC patients }\end{array}$ & $\begin{array}{l}\text { Frequency in 2 } \\
\text { group UC patients }\end{array}$ & 95\% CI & $\mathrm{p}$ \\
\hline Acute infusion reaction & $3 / 56$ & $1 / 84$ & $0.48-42.18$ & 0,87 \\
\hline Fever & $16 / 56$ & $1 / 84$ & $3.27-175.89$ & 0.0000043 \\
\hline Serious infectious complications & $1 / 56$ & $5 / 84$ & $0.04-2.5$ & 0.44 \\
\hline Non-serious infectious complications & $7 / 56$ & $14 / 84$ & $1.5-23.58$ & 0,66 \\
\hline Malignancy & $1 / 56$ & $4 / 84$ & $0.05-4.96$ & 0,97 \\
\hline Lethal cases & $1 / 56$ & $1 / 56$ & $0.1-23.49$ & 0,66 \\
\hline
\end{tabular}

Table 3 Summary analysis of side effects, occurred after MSC injection and in control group of patients with CD

\begin{tabular}{|l|l|l|l|c|}
\hline $\begin{array}{l}\text { Side effects in all analyzed clinical } \\
\text { trials }\end{array}$ & $\begin{array}{c}\text { Frequency in 3 } \\
\text { group CD patients }\end{array}$ & $\begin{array}{c}\text { Frequencies in 4 } \\
\text { group CD patients }\end{array}$ & $95 \%$ CI & $\mathrm{p}$ \\
\hline Acute infusion reaction & $2 / 47$ & 0 & - & 0.07 \\
\hline Fever & $22 / 47$ & 0 & $8.1-422.0$ & $<0.001$ \\
\hline Serious infectious complications & $1 / 47$ & $3 / 124$ & $0.09-1.85$ & 0.7 \\
\hline Non-serious infectious complications & $12 / 47$ & $48 / 124$ & $1.5-23.58$ & 0,66 \\
\hline Malignancy & 0 & $2 / 124$ & - & 0.93 \\
\hline Lethal cases & 0 & 1 & - & 0,61 \\
\hline
\end{tabular}

Third group included $47 \mathrm{CD}$ patients; mean follow-up period was $64 \pm 4$ months. Nineteen $(40,4 \%)$ man and twenty-eight $(59,26 \%)$ women were included in the third group. Mean age was $30,4 \pm 1,2$ years. Fourth control group consisted of $124 \mathrm{CD}$ patients, receiving standard anti-inflammatory therapy including 5-ASA, GCS and IS. In this group were $56(45,2 \%)$ man and $68(54,8 \%)$ women. Mean age was- $36,8 \pm 1,5$ years.

We did not include patients, receiving anti-TNF therapy, in analyzed groups.

Technique of receiving and cultivation MSC in an appropriate for systemic transplantation amount (150-200 millions of cells) was published [46]. This method is validated by Federal Supervisory Agency for Health Care and Social Development Ministry of Healthcare and Social Development of the Russian Federation (License 2006/206). Bone marrow cells were isolated by means of flushing the sternum or iliac crest of healthy donor under local anesthesia and aseptic conditions. All donors signed informed consent for using bone marrow samples for scientific purposes. MSC culture was injected intravenous drip-feed in dosage $1,5-2 \mathrm{mln}$ by $1 \mathrm{~kg}$ body weight. For systemic transplantation 130-160 mln allogenic MSC, cultivated, were suspended in $200 \mathrm{ml}$ sterile isotonic solution, consisting of heparin in concentration $50 \mathrm{U} / \mathrm{ml}$. MSC culture was injected during 40-60 minutes by means of intravenous drip-feed infusion. Mathematical modeling of MSC treatment was performed to assess maximal efficacy and minimal side effects of MSCs. We analyzed several trials, in which regimen of MSC administration, frequency and the rationale for the cell dose were examined $[13,14,44,45]$. All patients signed inform consent for participating in study before MSC injection. Thus, procedure of MSC cultivation was performed according GMP. Safety of therapy was assessed by presence of complications, occurred during follow-up period, for example acute infusional toxicity, fever; complications (neurological, pulmonary, cardiovascular (arrhythmias e.t.c), urinary, gastrointestinal tract and blood system), infection complications, exacerbation of chronic inflammatory diseases, serious infectious complications (pneumonia, sepsis, abscess), malignancy, death. All persons, monitoring the complications were blinded with the treatment.

\section{Results and Discussion}

In the first group $3 / 56$ UC patients $(5,4 \%)$ have acute infusional toxicitylooks like hives immediately or after MSC injection, in the second group allergic reaction like papulear urticaria was noticed in $1 / 84(1,2 \%)$ patient, 
treated with sulfasalazin. Allergic reaction like hives in first group patients had no statistically significance in compare with second group of patients $\left(\mathrm{x}^{2}-\right.$ $0,35 ; \mathrm{p}=0.87)$. In $16 / 56(28,6 \%)$ patients of first group were noted increasing of temperature around $37,2-37,4^{\circ} \mathrm{C}$ during 12 hours after MSC injection or fever around $38,0^{\circ} \mathrm{C}$, in $1 / 84(1,2 \%)$ patients of second group was reported increasing temperature above $37,7^{\circ}$, caused by intravenous injection of prednisolon. Fever and temperature increasing after MSC injection were statistically significant compared to control group - relative risk (RR) was $24,0(95 \%$ CI $3.27-175.89) ; x^{2}-21,12 ; p=0.0000043$. In the first UC group non-serious infectious complications and exacerbation of chronic inflammatory diseases were revealed in $7 / 56(12,5 \%)$ patients, in second group - in 14/84 (16,7\%) patients. There was no significant difference in risk of infectious complications and exacerbation of chronic inflammatory diseases between two groups of UC patient, receiving standard anti-inflammatory therapy and MSC (RR-0,75; 95\% CI 1.5-23.58; $\mathrm{x}^{2}-0,16 ; \mathrm{p}=0.66$ ). In the first group serious infectious complications (pneumonia, pleurisy, activation of latent tuberculosis) were detected in $1 / 56$ patients $(1,8 \%)$, in the second in $5 / 84(5,9 \%)$. There was no difference in this complications between two groups (RR-0,3; 95\%CI 0.04-2.5; $\mathrm{x}^{2}-0,59 ; \mathrm{p}=0.44$ ). Colorectal cancer was documented only in $1 / 56(1,8 \%)$ patient in the first group. Diagnosis of colon cancer was established in 10 days after MSC injection.

During five-year follow-up period malignancy was found in $4 / 84(4,8 \%)$ in the second group (RR-0,5, 95\%CI 0.05-4.96; $\mathrm{x}^{2}-0,01 ; \mathrm{p}=0.97$ ). In the first and in the second groups during five-year follow-up one lethal case from each group was documented and it was $1,8 \%$ и $1,2 \%$, respectively (RR-1,5; 95\%CI 0.1-23.49; $\mathrm{x}^{2}-0,19 ; \mathrm{p}=0.66$ ).

In the third group of $\mathrm{CD}$ patients acute infusional toxicity like hives and Quincke's edema were detected in $2 / 47$ patients $(4,25 \%)$ immediately after MSC injection, in the fourth group there were no complications during anti-inflammatory therapy, but these manifestations have no statistically significance between groups $\left(\mathrm{x}^{2}-2,3, \mathrm{p}=0.07\right)$. Increase in body temperature up to $37,2-37,4^{\circ} \mathrm{C}$ during 12 hours after MSC injection or fever up to $38,0^{\circ} \mathrm{C}$ was noticed in 22 patients of third group $(46,8 \%)$, in the fourth group of patients there was no fever, associated with intravenous interventions (medication injection) or per os administration was found in $0 / 124(0 \%)$. Fever and mild increase of temperature after MSC injection were statistically significant compare to control group - RR - 58,5 (95\% CI 8.1 - 422.0), $\mathrm{x}^{2}$ $58,5, \mathrm{p}<0.001$. Non-serious infectious complications and exacerbation of chronic inflammatory diseases during therapy observed in 12 patients of 47 in the third group, that accounts $25,5 \%$, in the fourth group-in $48(38,7 \%)$ patients of 124 , that had no significant difference: RR - 0,67 (95\% CI 0.39 1.15), $\mathrm{x}^{2}-1,86, \mathrm{p}=0.17$.

There were no differences between third and fourth groups in risk of serious infectious complications (pneumonia, peurisy, activation of latent tuberculosis) during standard anti-inflammatory $\mathrm{CD}$ therapy and therapy with MSC. In the third group one patient developed pneumonia $1 / 47(2,1 \%)$, in the fourth group two cases of pneumonia and one case of latent tuberculosis activation were detected - 3/124 (2,4\%) (RR-0,88, 95\%CI 0.09-1.85; $\mathrm{x}^{2}$ $0,21 ; \mathrm{p}=0.7)$.
In the third group of CD patients no cases of colorectal cancer were found. In the third group during five-year follow-up period no lethal outcomes were documented, in the fourth group one lethal case $(0,8 \%)$, unlinked to underlying disease was found $\left(\mathrm{x}^{2}-0,26 ; \mathrm{p}=0.61\right)$. In the fourth group malignant transformation was noted in 2 patients $(1,6 \%)$ from $124\left(\mathrm{x}^{2}-0,01 ; \mathrm{p}=0.93\right)$.

In patients with $\mathrm{UC}$ and $\mathrm{CD}$, receiving MSC treatment, no cardiovascular, pulmonary, neurological, renal, and hematologic systems complications were detected.

\section{Conclusion}

Our study includes comparative analysis of adverse events, associated with MSC treatment and standard anti-inflammatory therapy in UC and CD patients. We analyzed advanced outcomes in 103 IBD patients, receiving MSC therapy and compared this data with $208 \mathrm{UC}$ and CD patients, who had the same demographic characteristics, disease duration, extent of disease, course of disease, phenotype of disease, type of severity. Thus we did not observe any significant differences in MSC safety, aside from transient fever.

This analysis did not reveal any differences in acute post transfusion toxicity, infectious complications, exacerbation of chronic inflammatory diseases, serious infectious complications, malignancy and lethal cases in UC and CD patients, treated with standard anti-inflammatory therapy.

We have detected significant association between MSC injection and fever. However, fever was transient and not associated with long term sequelae. The mechanisms for fever are not clear but could be related to acute inflammatory reactions by a subset of patients to particular preparations of MSCs, not unlike similar reactions occasionally observed with red blood cell and fresh frozen plasma administration [47].

Although malignant transformation is a theoretical risk, our own experience and literature analysis, presented in this review found no association between MSCs and tumor formation. Concerns related to tumorigenicity of MSCs were raised by preclinical studies demonstrating increased tumor burden in vivo [48]. Although recent position papers have suggested low probability of malignant transformation and tumor formation with MSCs [8]. Malignancy occurred only in studies involving participants with ongoing or previous malignancies; no de novo malignancies were observed.

Although MSC immunomodulatory effects may be beneficial in proinflammatory diseases, these same effects may leave a patient susceptible to infection. [49]. The question raised-whether immunosuppressive therapy could increase risk of infections? This review did not demonstrate any evidence of increased susceptibility to infections with MSC administration.

In our review, infections were common in already immunosuppressed patients (e.g. following hematopoietic stem cell transplant), however the infection rates were similar to those in control group of patients [47]. 
Currently obtained data show that despite of strong immunosuppressive effect due to autoimmune aggression, MSC did not hinder the activity of immunocompetent cells, directed against infectious agents [50-56].

Absence of posttransfusional reaction may be explained by low MSC immunogenicity, due to absence HLA class II and low level of expression HLA I class at their surface [57]. The use of fetal bovine serum for culturing MSCs could be one of the reasons for above mentioned post-transfusion toxicity, and another potential concern with MSC therapy application is the use of dimethylsulfoxide as criopreservative, which has toxic side effects and could cause hypersensitivity reactions $[58,59]$. Thus, greater vigilance may be needed in future studies for reporting cellular viability and monitoring for potential dimethylsulfoxide related adverse events. Results from our study should provide some assurance to investigators and health regulators that, with the present evidence, this innovative therapy appears safe.

\section{Reference}

1. Friedenstein AJ, Piatetzky-Shapiro II, Petrakova KV (1966) Osteogenesis in transplants of bone marrow cells. J Embryol Exp Morphol 16: 381390 .

2. François $\mathrm{S}$, Bensidhoum $\mathrm{M}$, Mouiseddine $\mathrm{M}$, Mazurier $\mathrm{C}$, Allenet B, et al. (2006) Local irradiation not only induces homing of human mesenchymal stem cells at exposed sites but promotes their widespread engraftment to multiple organs: a study of their quantitative distribution after irradiation damage. Stem Cells 24:. 1020-1029.

3. Matthay MA, Goolaerts A, Howard JP, Lee JW (2010) Mesenchymal stem cells for acute lung injury: preclinical evidence. Crit Care Med 38: S569-S573.

4. Mei SH, McCarter SD, Deng Y, Parker CH, Liles WC, et al. (2007) Prevention of LPS-induced acute lung injury in mice by mesenchymal stem cells overexpressing angiopoietin. PLoS Med 4: e269.

5. Mei SHJ, Haitsma JJ, Dos Santos CC, Deng Y, Lai PFH, et al. (2010) Mesenchymal stem cells reduce inflammation while enhancing bacterial clearance and improving survival in sepsis. Am J Respir Crit Care Med 182: 1047-1057.

6. Boyle AJ, McNiece IK, Hare JM (2010) Mesenchymal stem cell therapy for cardiac repair. Methods Mol Biol 660: 65-84.

7. Knyazev OV, Parfenov AI, Sherbakov PL, Homeriki SG, Ruchkina IN, et al. (2013) Efficacy and safety of mesenchymal stem cells in patients with refractory Crohn disease. Cell transplantation and tissue engineering. VIII: 76-84.

8. Prockop DJ, Brenner M, Fibbe WE, Horwitz E, Le Blanc K, et al. (2010) Defining the risks of mesenchymal stromal cell therapy. Cytotherapy 12: 576-578.

9. Lalu MM, McIntyre L, Pugliese C, Fergusson D, Winston BW, et al. (2012) Safety of Cell Therapy with Mesenchymal Stromal Cells (Safe Cell): A Systematic Review and Meta-Analysis of Clinical Trials. PLoS One 7: e47559.
10. Chen S, Liu Z, Tian N, Zhang J, Yei F, et al. (2006) Intracoronary transplantation of autologous bone marrow mesenchymal stem cells for ischemic cardiomyopathy due to isolated chronic occluded left anterior descending artery. J Invasive Cardiol 18: 552-556.

11. Chen SL, Fang WW, Qian J, Ye F, Liu YH, et al. (2004) Improvement of cardiac function after transplantation of autologous bone marrow mesenchymal stem cells in patients with acute myocardial infarction. Chin Med J 117: 1443-1448.

12. Hare JM, Traverse JH, Henry TD, Dib N, Strumpf RK, et al. (2009) A randomized, double-blind, placebo-controlled, dose-escalation study of intravenous adult human mesenchymal stem cells (prochymal) after acute myocardial infarction. J Am Coll Cardiol 54: 2277-2286.

13. Lee JS, Hong JM, Moon GJ, Lee PH, Ahn YH, et al. (2010) A longterm follow-up study of intravenous autologous mesenchymal stem cell transplantation in patients with ischemic stroke. Stem Cells 28: 10991106.

14. Lee PH, Kim JW, Bang OY, Ahn YH, Joo IS, et al. (2010) Autologous mesenchymal stem cell therapy delays the progression of neurological deficits in patients with multiple system atrophy. Clin Pharmacol Ther 83: 723-730.

15. Ning H, Yang F, Jiang M, Hu L, Feng K, et al. (2008) The correlation between cotransplantation of mesenchymal stem cells and higher recurrence rate in hematologic malignancy patients: outcome of a pilot clinical study. Leukemia 22: 593-599.

16. Wang JA, Xie XJ, He H, Sun Y, Jiang J, et al. (2006) A prospective, randomized, controlled trial of autologous mesenchymal stem cells transplantation for dilated cardiomyopathy. Zhonghua Xin Xue Guan Bing Za Zhi 34: 107-110.

17. Xie ZW, Cui GX, Li YZ, Li BW, Zhu SW, et al. (2007) Curative effect of autologous mesenchymal stem cell transplantation on spinal cord injury. J Clin Rehabilitat Tiss Eng Res 11: 1277-1279.

18. Baron F, Lechanteur C, Willems E, Bruck F, Baudoux E, et al. (2010) Cotransplantation of mesenchymal stem cells might prevent death from graft-versus-host disease (GVHD) without abrogating graftversus-tumor effects after HLA-mismatched allogeneic transplantation following nonmyeloablative conditioning. Biol Blood Marrow Transplant 16: 838-847.

19. Gonzalo-Daganzo R, Regidor C, Martin-Donaire T, Rico MA, Bautista G, et al. (2009) Results of a pilot study on the use of third-party donor mesenchymal stromal cells in cord blood transplantation in adults. Cytotherapy 11: 278-288.

20. Kebriaei P, Isola L, Bahceci E, Holland K, Rowley S, et al. (2009) Adult human mesenchymal stem cells added to corticosteroid therapy for the treatment of acute graft-versus-host disease. Biol Blood Marrow Transplant 15: 804-811.

21. Koc ON, Day J, Nieder M, Gerson SL, Lazarus HM, et al. (2008) Allogeneic mesenchymal stem cell infusion for treatment of metachromatic leukodystrophy (MLD) and Hurler syndrome (MPSIH). Bone Marrow Transplant 30: 215-222. 
22. Lazarus HM, Haynesworth SE, Gerson SL, Rosenthal NS, Caplan AI (1995) Ex vivo expansion and subsequent infusion of human bone marrow-derived stromal progenitor cells (mesenchymal progenitor cells): implications for therapeutic use. Bone Marrow Transplant 16: 557-564.

23. Lazarus HM, Koc ON, Devine SM, Curtin P, Maziarz RT, et al. (2005) Cotransplantation of HLA-identical sibling culture-expanded mesenchymal stem cells and hematopoietic stem cells in hematologic malignancy patients. Biol Blood Marrow Transplant 11: 389-398.

24. Liu L, Sun Z, Chen B, Han Q, Liao L, et al. (2006) Ex vivo expansion and in vivo infusion of bone marrow-derived Flk-1+CD31-CD34mesenchymal stem cells: feasibility and safety from monkey to human. Stem Cells Dev 15: 349-357.

25. Mohyeddin-Bonab M, Mohamad-Hassani MR, Alimoghaddam K, Sanatkar M, Gasemi M, et al. (2007) Autologous in vitro expanded mesenchymal stem cell therapy for human old myocardial infarction. Arch Iran Med 10: 467-473.

26. Ringden O, Uzunel M, Rasmusson I, Remberger M, Sundberg B, et al. (2006) Mesenchymal stem cells for treatment of therapy-resistant graftversus-host disease. Transplantation 81: 1390-1397.

27. Vanikar AV, Trivedi HL, Feroze A, Kanodia KV, Dave SD, et al. (2011) Effect of co-transplantation of mesenchymal stem cells and hematopoietic stem cells as compared to hematopoietic stem cell transplantation alone in renal transplantation to achieve donor hypo-responsiveness. Int Urol Nephrol 43: 225-232.

28. Arima N, Nakamura F, Fukunaga A, Hirata H, Machida H, et al. (2010) Single intra-arterial injection of mesenchymal stromal cells for treatment of steroid-refractory acute graft-versus-host disease: a pilot study. Cytotherapy 12: 265-268.

29. Duijvestein M, Vos AC, Roelofs H, Wildenberg ME, Wendrich BB, et al. (2010) Autologous bone marrow-derived mesenchymal stromal cell treatment for refractory luminal Crohn's disease: results of a phase I study. Gut 59: 1662-1669.

30. Fang B, Song Y, Liao L, Zhang Y, Zhao RC (2007) Favorable response to human adipose tissue-derived mesenchymal stem cells in steroidrefractory acute graft-versus-host disease. Transplant Proc 39: 33583362.

31. Honmou O, Houkin K, Matsunaga T, Niitsu Y, Ishiai S, et al. (2011) Intravenous administration of auto serum-expanded autologous mesenchymal stem cells in stroke. Brain 134: 1790-1807.

32. Karussis D, Karageorgiou C, Vaknin-Dembinsky A, Gowda-Kurkalli B, Gomori JM, et al. (2010) Safety and immunological effects of mesenchymal stem cell transplantation in patients with multiple sclerosis and amyotrophic lateral sclerosis. Arch Neurol 67: 1187-1194.

33. Le Blanc K, Frassoni F, Ball L, Locatelli F, Roelofs H, et al. (2008) Mesenchymal stem cells for treatment of steroid-resistant, severe, acute graft-versus-host disease: a phase II study. Lancet 371: 1579-1586.
34. Liang J, Zhang H, Hua B, Wang H, Lu L, et al. (2010) Allogenic mesenchymal stem cells transplantation in refractory systemic lupus erythematosus: a pilot clinical study. Ann Rheum Dis 69: 1423-1429.

35. Liang J, Zhang H, Wang D, Feng X, Wang H, et al. (2012) Allogeneic mesenchymal stem cell transplantation in seven patients with refractory inflammatory bowel disease. Gut 61: 468-469.

36. Meuleman N, Tondreau T, Ahmad I, Kwan J, Crokaert F, et al. (2009) Infusion of mesenchymal stromal cells can aid hematopoietic recovery following allogeneic hematopoietic stem cell myeloablative transplant: a pilot study. Stem Cells Dev 18: 1247-1252.

37. Mohamadnejad M, Alimoghaddam K, Mohyeddin-Bonab M, Bagheri M, Bashtar M, et al. (2007) Phase 1 trial of autologous bone marrow mesenchymal stem cell transplantation in patients with decompensated liver cirrhosis. Arch Iran Med 10: 459-466.

38. Ringden O, Uzunel M, Sundberg B, Lonnies L, Nava S, et al. (2007) Tissue repair using allogeneic mesenchymal stem cells for hemorrhagic cystitis, pneumomediastinum and perforated colon. Leukemia 21: 22712276.

39. Sun L, Akiyama K, Zhang H, Yamaza T, Hou Y, et al. (2009) Mesenchymal stem cell transplantation reverses multiorgan dysfunction in systemic lupus erythematosus mice and humans. Stem Cells 27: 1421-1432.

40. Sun L, Wang D, Liang J, Zhang H, Feng X, et al. (2010) Umbilical cord mesenchymal stem cell transplantation in severe and refractory systemic lupus erythematosus. Arthritis Rheum 62: 2467-2475.

41. Wang D, Zhang H, Cao M, Tang Y, Liang J, et al. (2011) Efficacy of allogeneic mesenchymal stem cell transplantation in patients with drugresistant polymyositis and dermatomyositis. Ann Rheum Dis 70: 12851288.

42. Weng JY, Du X, Geng SX, Peng YW, Wang Z, et al. (2010) Mesenchymal stem cell as salvage treatment for refractory chronic GVHD. Bone Marrow Transplant 45: 1732-1740.

43. Yang Z, Zhang F, Ma W, Chen B, Zhou F, et al. (2010) A novel approach to transplanting bone marrow stem cells to repair human myocardial infarction: delivery via a noninfarct-relative artery. Cardiovasc Ther 28: 380-385.

44. Zhang X, Li JY, Cao K, Lu H, Hong M, et al. (2010) Cotransplantation of HLA-identical mesenchymal stem cells and hematopoietic stem cells in Chinese patients with hematologic diseases. Int J Lab Hematol 32: 256264.

45. Zhang ZX, Guan LX, Zhang K, Zhang Q, Dai LJ (2008) A combined procedure to deliver autologous mesenchymal stromal cells to patients with traumatic brain injury. Cytotherapy 10: 134-139.

46. Zib AF, Konoplyannikov AG, Kolesnikova AI, Pavlov VV (2004) Application of cell cultures in medicine from mesenchymal stem cells of human bone marrow. News of Russian Academy of science 59: 71-76. 
47. Hendrickson JE, Hillyer CD (2009) Noninfectious serious hazards of transfusion. Anesth Analg 108: 759-769.

48. Djouad F, Plence P, Bony C, Tropel P, Apparailly F, et al. (2003) Immunosuppressive effect of mesenchymal stem cells favors tumor growth in allogeneic animals. Blood 102: 3837-3844.

49. Uccelli A, Moretta L, Pistoia V (2008) Mesenchymal stem cells in health and disease. Nat Rev Immunol 8: 726-736.
50. Karlsson H, Samarasinghe S, Ball LM, Sundberg B, Lankester AC, et al. (2008) Mesenchymal stem cells exert differential effects on alloantigen and virus-specific T-cell responses. Blood 112: 532-541.

51. Majumdar MK, Keane-Moore M, Buyaner D, Hardy WB, Moorman MA, et al. (2003) Characterization and functionality of cells surface molecules on human mesenchymal stem cell. J Biomed Sci 10: 228-241.

Submit your manuscript at

http://enlivenarchive.org/submit-manuscript.php

New initiative of Enliven Archive

Apart from providing HTML, PDF versions; we also provide video version and deposit the videos in about 15 freely accessible social network sites that promote videos which in turn will aid in rapid circulation of articles published with us. 